\title{
Correction to: Note on Forcing Problem of Trees
}

\section{Mengya $\mathrm{He}^{1} \cdot$ Shengjin $\mathrm{Ji}^{1}$}

Published online: 24 January 2022

(C) Springer Japan KK, part of Springer Nature 2022

\section{Correction to: Graphs and Combinatorics https://doi.org/10.1007/s00373-021-02402-w}

In the original publication, several author's corrections were inadvertently missed out during production process. The original article has been corrected.

Publisher's Note Springer Nature remains neutral with regard to jurisdictional claims in published maps and institutional affiliations.

The original article can be found online at https://doi.org/10.1007/s00373-021-02402-w.

Shengjin Ji

jishengjin@sdut.edu.cn

Mengya He

m19811737859@163.com

1 School of Mathematics and Statistics, Shandong University of Technology,

Zibo 255049, Shandong, People's Republic of China 